\title{
Statistics and Analysis of the Results of the First-Class Think Tanks in the United States
}

\author{
Jiayin Liu, Jilun Li, Jing Qin \\ Nanjing University of Aeronautics and Astronautics, Nanjing, China \\ Email: 1337569531@qq.com
}

How to cite this paper: Liu, J.Y., Li, J.L. and Qin, J. (2020) Statistics and Analysis of the Results of the First-Class Think Tanks in the United States. Open Access Library Journal, 7: e6005.

https://doi.org/10.4236/oalib.1106005

Received: December 16, 2019

Accepted: January 11, 2020

Published: January 14, 2020

Copyright $\odot 2020$ by author(s) and Open Access Library Inc.

This work is licensed under the Creative Commons Attribution International License (CC BY 4.0).

http://creativecommons.org/licenses/by/4.0/

\begin{abstract}
This article conducts quantitative analysis and research on the results of the first-class think tanks in the United States, and aims to provide reference for China's developing first-rate think tanks and provide suggestions for future development routes. This article uses Elsevier's Scopus database and SciVal analysis platform to quantitatively analyze the research results of 5 first-class think tanks in the United States in the past 10 years, using indicators such as $\mathrm{h}$ index, normalized impact factor, and high cited literature ratio to make a horizontal comparison of the development trends of the institutions, and further summarize and analyze on this basis. Through the analysis and research of the results of the five first-class think tanks in the United States, it provides a quantitative and in-depth important reference for China to build a world-class think tank.
\end{abstract}

\section{Subject Areas}

Education, Sociology

\section{Keywords}

Think Tank, Think Tank Results, Think Tanks in the United States, SciVal

\section{Introduction}

The think tank is a non-profit organization that aims at enlightening the people and conducting scientific research and analysis of public policies through scientific and professional perspectives. On October 27, 2014, the Sixth Meeting of the Leading Group of the Central Committee of Comprehensive and Deepening Reform reviewed the "Opinions on Strengthening the Construction of New Type Think Tanks with Chinese Characteristics" [1]. General Secretary Xi and the 
leaders of the CPC Central Committee have presided over and held conferences and expert forums many times to implement the construction of a socialist think tank with Chinese characteristics and provide important support for the party and government's scientific and democratic decision-making [2]. The decision-making consultation system is an important part of China's socialist democratic politics. How to build and develop China's think tanks into world-class think tanks is an important issue that needs to be solved at present. Since 2015, the construction of Chinese think tanks has entered a stage of high-speed development. In 2015, it was called the first year of Chinese think tanks [3].

To build a world-class think tank, we must first thoroughly study and understand the world-class think tank. The Think Tank and Citizenship Project hosted by Dr. McGan of the University of Pennsylvania released the most authoritative Global Think Tank Report 2017 on January 30, 2018. This is the $11^{\text {th }}$ consecutive year that the organization has comprehensively reviewed global think tanks. In the Global Think Tank Report 2017, seven Chinese think tanks have been selected as the world-class think tanks of the evaluation system, but it is undeniable that there is still a significant gap between China's think tank construction and world-class countries. As the world's top think tanks, the Brookings Institution and the Rand Corporation in the United States have spread their knowledge and thoughts in different ways, promoted innovation, and promoted social productivity. They have an extremely high status and voice in the world [4].

The research object of this article is to select the top American think tanks in the Global Think Tank Report 2017 [5] [6]. Through the statistics and analysis of the results of the first-class think tanks in the United States, the characteristics of the results of the first-class think tanks in the United States and where they come from are designed to develop the world for China. The first-class think tank provides a reference for the future development route [7].

\section{Data Sources and Analysis Tools}

\subsection{SciVal's Data Sources}

The literature data in SciVal is from the Scopus database. Scopus database users can adjust academic indicators according to their needs, and display a full range of scientific research capabilities on the physical institutions existing or customized in SciVal and Scopus databases [8].

\subsection{Selection and Principle of SciVal Index}

SciVal's academic indicators are provided by Snowball Metrics. This indicator was created by an institution composed of experts from the world's top universities such as Imperial College of Technology, Cambridge University, etc., and aims to meet the general needs in scientific research. The specific calculation methods and principles of all indicators are included in the third edition of the Snowball Metrics Recipe Book [9]. 


\subsubsection{Scholarly Output Indicator}

Scholarly output counts the number of outcome outputs for any type of institution. The data source of this article is the literature data included in the Scopus database that contains the above types of achievements [10].

\subsubsection{Citation Indicators}

The total Citation Count is the sum of the number of citations received by the institution's output and represents the academic impact of the output.

The Field-Weighted Citation Impact Factor is defined as the ratio of the actual citations of documents received by the institution to the citations received by similar publications of all other institutions in the subject area [11].

Publications in Top Journal Percentiles are the number of documents published in top journals in all publications of the institution. Metrics for the percentage of top journals This article selects the SNIP (Source Normalized Impact per Paper) indicator provided by Cite Score from 2011 [12].

\subsubsection{H-Index}

The $\mathrm{h}$ index is a mixed quantitative index, and its purpose is to quantify the research results of scientific researchers as independent individuals. The $h$ index of a scientist or institution means that among the published Np papers, h papers are cited at least $\mathrm{h}$ times, and the remaining $\mathrm{Np}$-h papers are cited less than or equal to $h$ times. If a scientist's publications are ranked by the number of their cited life cycle, then the $\mathrm{h}$ index is a maximum value, which means that each article has been cited at least $h$ times by $h$ articles [13].

\subsubsection{Spotlight Cross-Disciplinary Analysis Tool (Discipline Area)}

Spotlight is an innovative cross-disciplinary analysis and cutting-edge domain analysis tool. It uses patented visualization technology to intuitively reflect the development status of interdisciplinary organizations, help plan discipline development, and promote international cooperation.

\section{Analysis and Research on the Results of the First-Class American Think Tanks}

Taking the "Global Think Tank Report 2017" as the main reference standard, and the total number of documents and total citations collected by the institutional entities in the Scopus database as the secondary reference standard, this article selects 5 top US think tanks in the report as samples of think tank. The first-class think tanks selected are: Brookings Institution, "Global Think Tank Report 2017" ranked first in the world; Carnegie Endowment for International Peace, "Global Think Tank Report 2017" ranked third in the world; Rand Corporation, "Global Think Tank Report 2017 ranked $9^{\text {th }}$ in the world; Urban Institute, Global Think Tank Report 2017 ranked $55^{\text {th }}$ in the world; Hudson Institute, Global Think Tank Report 2017 ranked $105^{\text {th }}$ in the world [14].

Statistical indicators use Scival to select the number of scholarly outputs, total citations, normalized impact factors, top $10 \%$ journal literature, and $\mathrm{h}$ indicators 
in the Benchmarking section in the past 10 years as statistical indicators for the analysis of think tank results [15]. Taking the Carnegie Endowment for International Peace as an example, Spotlight is used to analyze the current state of development of the institution's disciplinary fields and its cross-disciplinary competitive advantages [16].

\subsection{Comparative Analysis of Scholarly Output}

Drawing the bar chart of the number of scholarly outputs in Table 1 according to the year of publication, we can see the trend of the output of the results of five first-class think tanks in the United States in the past decade. By comparing the results, we analyze the factors that affect the academic output of five top American think tanks (Figure 1).

In the horizontal comparison of the scholarly output of the five first-class think tanks, the output of Carnegie Endowment for International Peace and Rand Corporation is significantly higher than the other three think tanks. In terms of academic output, the Carnegie Endowment for International Peace has 438\% more academic output than Brookings Institution, 35\% more than Rand Corporation, 968\% more than Urban Institute and 195\% higher than Derson Institute.

Table 1. Overview of the achievement indicators of five top-ranked U.S. think tanks.

\begin{tabular}{cccccc}
\hline Think tank & $\begin{array}{c}\text { Brookings } \\
\text { Institution }\end{array}$ & $\begin{array}{c}\text { Carnegie } \\
\text { Institution }\end{array}$ & $\begin{array}{c}\text { RAND } \\
\text { Corporation }\end{array}$ & $\begin{array}{c}\text { Urban } \\
\text { Institute }\end{array}$ & $\begin{array}{c}\text { Hudson } \\
\text { Institute }\end{array}$ \\
\hline $\begin{array}{c}\text { Academic output } \\
\text { Total Citations (excluding } \\
\text { self-citations) }\end{array}$ & 1368 & 7362 & 5440 & 689 & 2495 \\
$\begin{array}{c}\text { Normalized Impact Factor } \\
\text { (excluding self-citation) }\end{array}$ & 1.538 & 1.901 & 1.947 & 1.418 & 1.56 \\
$\begin{array}{c}\text { Number of top 10\% journal } \\
\text { articles (SNIP) }\end{array}$ & 129 & 214682 & 83609 & 6658 & 49689 \\
h index & 24 & 2794 & 990 & 91 & 647 \\
\hline
\end{tabular}

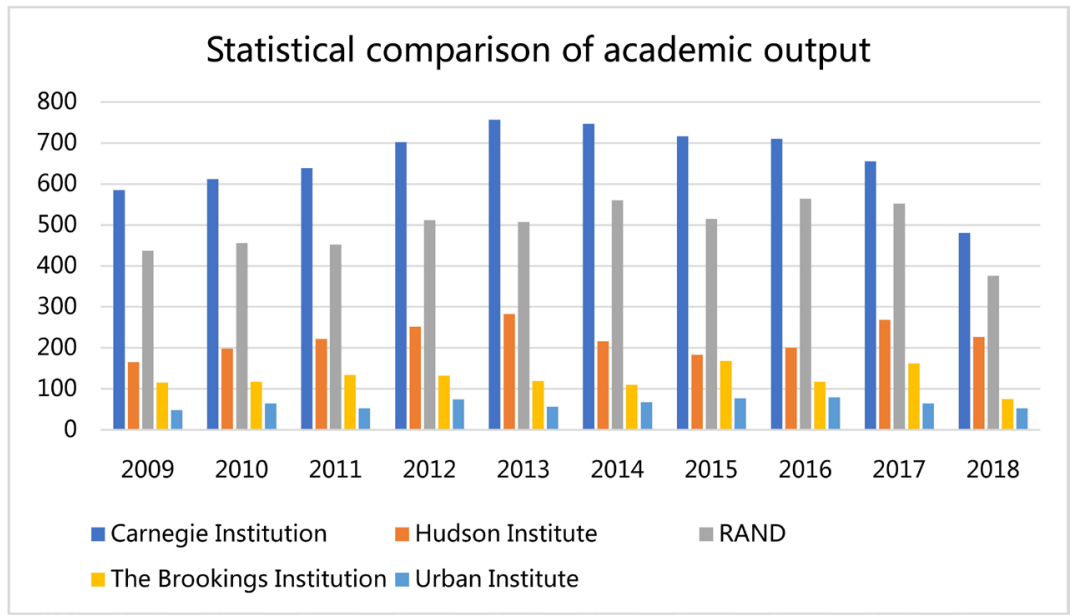

Figure 1. Statistical comparison of academic output. 
RAND ranks second in the comparison of the number of academic outputs in this article. As the world's most well-known non-profit private think tank and consulting agency, RAND Corporation can rank among the best in academic output because the RAND Corporation has its distinctive features even among many first-class think tanks in the United States. The independence of RAND's organization and operation is very high. With its high-quality products, its relationship with the US government is not dependent. The company's business is spread all over the world, from the US federal and state governments, foreign governments, private enterprises and individuals, etc. A variety of customers and needs, combined with RAND's high-quality, high-profile, and forward-looking subject research, have kept RAND's academic output at a high level.

The City Institute and Hudson College ranked third and fifth respectively in the comparison of the number of academic outputs in this article. Compared with the three American first-class think tanks with long history and huge scale system mentioned earlier in this article, the Urban Research Institute and Hudson College are two smaller think tanks with more unified functions. The Urban Research Institute aims to study urban issues in the country. The main research topics are public policies, such as retirement and aging, health care, education, income and welfare, etc. As of 2017, the federal government and foundations have occupied the research $80 \%$ of all income. Hudson College was founded by Herman Kahn in 1961 after separating from Rand Corporation. After the $21^{\text {st }}$ century, the college has been focusing on international issues such as the Middle East, Latin America, and Islam, and its main research and development products are mostly related to national security and foreign policy issues. The Carnegie Endowment for International Peace ranks first in statistics for the number of academic outputs in this article. As the first think tank on international affairs in the United States, the Foundation has always adapted to the times and constantly innovated. From the organization's income and expenditure statement, since 2015 , the think tank's investment income has accounted for about $45 \%$ of the foundation's total income, and the other half of the funds are guaranteed by donations from all parties. In the past three years, salary expenditures and employee benefits accounted for $50 \%$ to $60 \%$ of the total expenditures. This shows that the foundation attaches great importance to the value and training of its talents. Excellent conditions and benefits allow researchers to focus on research and promote results. Taking all these factors into consideration, the Foundation's rankings in the Global Think Tank Report have improved significantly in recent years, ranking first in the number of academic outputs of think tank results.

The Brookings Institution's academic output statistics are limited by the methods of data source acquisition and access, and it ranks fourth in the comparison of this article. Comprehensively analyzing, on the one hand, the reason is that the diversity of data sources is insufficient. The main types of think tank results included in the Scopus database are printed materials such as conference documents, academic papers, and periodical publications. There are insufficient 
and incomplete issues in the literature collection. On the other hand, the more important reason is that the Brookings Institution has always provided the government with public policy advice and innovative ideas as the main source of primary productivity and business revenue. In $2017,82.5 \%$ of the Brookings Institution's huge income of US $\$ 117,336,000$ came from government grants and contracts. The outcomes of the Brookings Institution and the U.S. federal government, local governments, and parties in international relations, international politics, and foreign policy are constrained by the type of literature and access rights. It is difficult to be quantified and analyzed. In the statistical comparison of academic achievements, there is a significant gap between the two other first-class think tanks.

The Carnegie Endowment for International Peace ranks first in statistics for the number of academic outputs in this article. As the first think tank on international affairs in the United States, the Foundation has always adapted to the times and constantly innovated. From the organization's income and expenditure statement, since 2015, the think tank's investment income has accounted for about $45 \%$ of the foundation's total income, and the other half of the funds are guaranteed by donations from all parties. In the past three years, salary expenditures and employee benefits accounted for $50 \%$ to $60 \%$ of the total expenditures. This shows that the foundation attaches great importance to the value and training of its talents. Excellent conditions and benefits allow researchers to focus on research and promote results. Taking all these factors into consideration, the Foundation's rankings in the Global Think Tank Report have improved significantly in recent years, ranking first in the number of academic outputs of think tank results.

Rand ranks second in the comparison of the number of academic outputs in this article. As the world's most well-known non-profit private think tank and consulting agency, Rand Corporation can rank among the best in academic output because the Rand Corporation has its distinctive features even among many first-class think tanks in the United States. The independence of Rand's organization and operation is very high. With its high-quality products, its relationship with the US government is not dependent. The company's business is spread all over the world, from the US federal and state governments, foreign governments, private enterprises and individuals, etc.. A variety of customers and needs, combined with Rand's high-quality, high-profile, and forward-looking subject research, have kept Rand's scholarly output at a high level.

The City Institute and Hudson College ranked third and fifth respectively in the comparison of the number of academic outputs in this article. Compared with the three American first-class think tanks with long history and huge scale system mentioned earlier in this article, the Urban Research Institute and Hudson College are two smaller think tanks with more unified functions. The Urban Research Institute aims to study urban issues in the country. The main research topics are public policies, such as retirement and aging, health care, education, 
income and welfare, etc. As of 2017, the federal government and foundations have occupied the $80 \%$ of all income. Hudson College was founded by Herman Kahn in 1961 after separating from Rand Corporation. After the $21^{\text {st }}$ century, the college has been focusing on international issues such as the Middle East, Latin America, and Islam, and its main research and development products are mostly related to national security and foreign policy issues.

\subsection{Statistical Analysis of Impact of Results}

This article analyzes the impact of the results of 5 top think tanks in the United States through two indicators, the Field-Weighted Citation Impact Factor in Figure 2 and the top 10\% journal (SNIP) publication volume in Figure 3, and delves into the reasons why the organization achieved such results.

A horizontal comparison of the Field-Weighted Citation Impact Factor of five first-class think tanks in the United States over the past 10 years. The Rand Corporation and Carnegie Endowment for International Peace rank the top two with average values of 1.947 and 1.901, respectively. The Kings Institute and the City Institute rank behind 1.56, 1.538, and 1.418, respectively. From the line chart, it can be seen that the Field-Weighted Citation Impact Factor of the think tank's results have a large fluctuation in the comprehensive impact of the year of receipt and the research area. In 2011, the Brookings Institution index reached 2.43, in 2014 the Carnegie Endowment for International Peace reached 2.16, in 2016 Hudson College reached 3.48, and in 2018, Rand Corporation reached 3.92.

Judging from the number of papers issued by top journals, the quality of Carnegie Endowment for International Peace's output is even greater. Under the SNIP's journal rating system, Carnegie Endowment for Peace issued $180 \%$ more paper than the second-ranked Rand Corporation in the top 10\%. In the statistics of this indicator, the performance of Hudson College has significantly increased compared to the total academic output, and in 2013 it surpassed Rand Corporation to rank second.

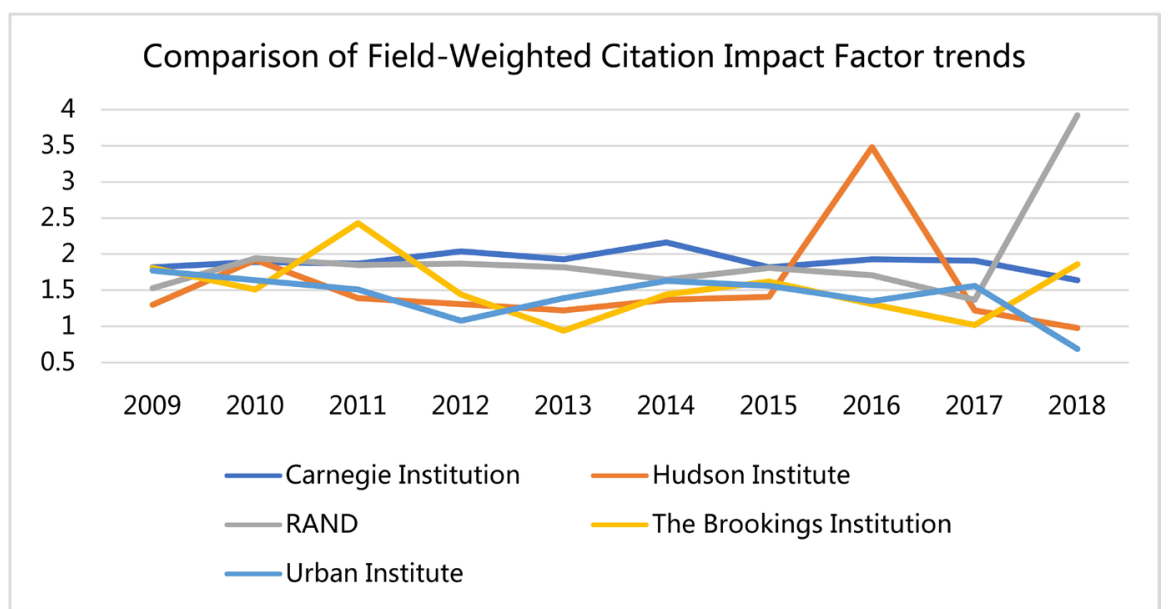

Figure 2. Comparison of Field-Weighted Citation Impact Factor trends. 
Trends in Top $10 \%$ Journals (SNIP)

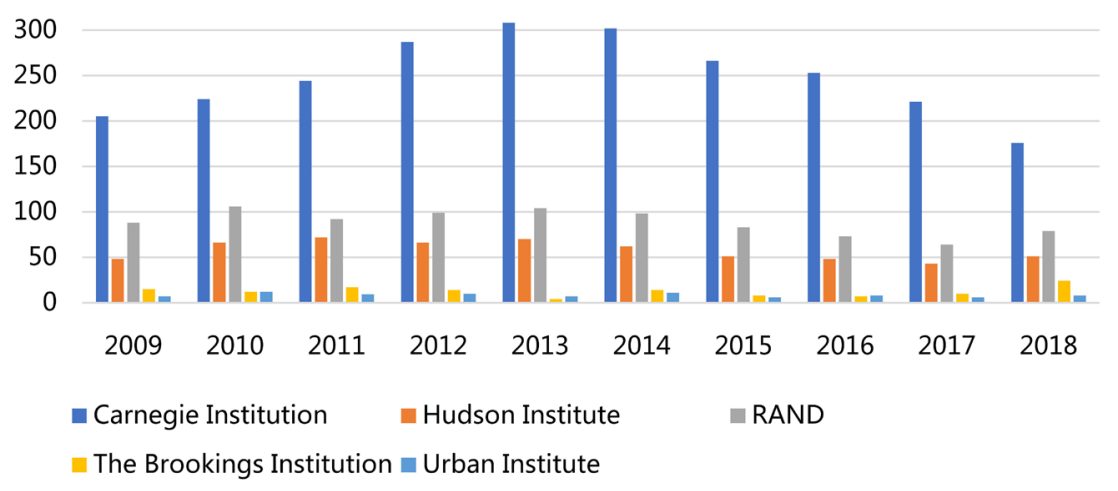

Figure 3. Trends in Top 10\% Journals (SNIP).

The Carnegie Endowment for International Peace still ranks ahead in terms of influence indicators. The Foundation has continuously launched research with high impact on the study of international relations and foreign policy issues and national defense and national security issues worldwide. Organizations not only measure the impact of reports through social tools such as Twitter, media clicks, or online click-through rates, but also focus on the quality, response, and life cycle of ideas to increase the impact of organizational results and organizational brand.

Rand Corporation ranked second in performance indicators. Rand Corporation has established an operation review mechanism in the entire process of output (development of R \& D, quality control, open channels, feedback evaluation), and has a set of mechanisms to review the research distribution within the company every 4 - 5 years to inspect whether the results of each research unit are valuable. Establishing an independent research culture and strict review and evaluation mechanism to control the company's operations and internal and external research into future development and research results, is the embodiment of Rand company in the output of scientific research results to achieve a unified quality and quantity.

\subsection{Analysis of Competitive Advantages of Frontiers and Interdisciplinary Disciplines}

Taking the Carnegie Endowment for International Peace as an example, it analyzes the interdisciplinary fields that think tanks have in their frontier research fields and their organizations have competitive advantages. The Carnegie Endowment for International Peace was selected as the institutional entity, and the top $1 \%$ of the highly cited literature of the institution in 2018 was extracted, and it is presented in Figure 4 according to the 27 fields in the Scopus database. Different colors represent different disciplines, corresponding to a circle of circles. Each circle represents a document aggregation, which is a cross-disciplinary competitive advantage. The size of the circle represents the 


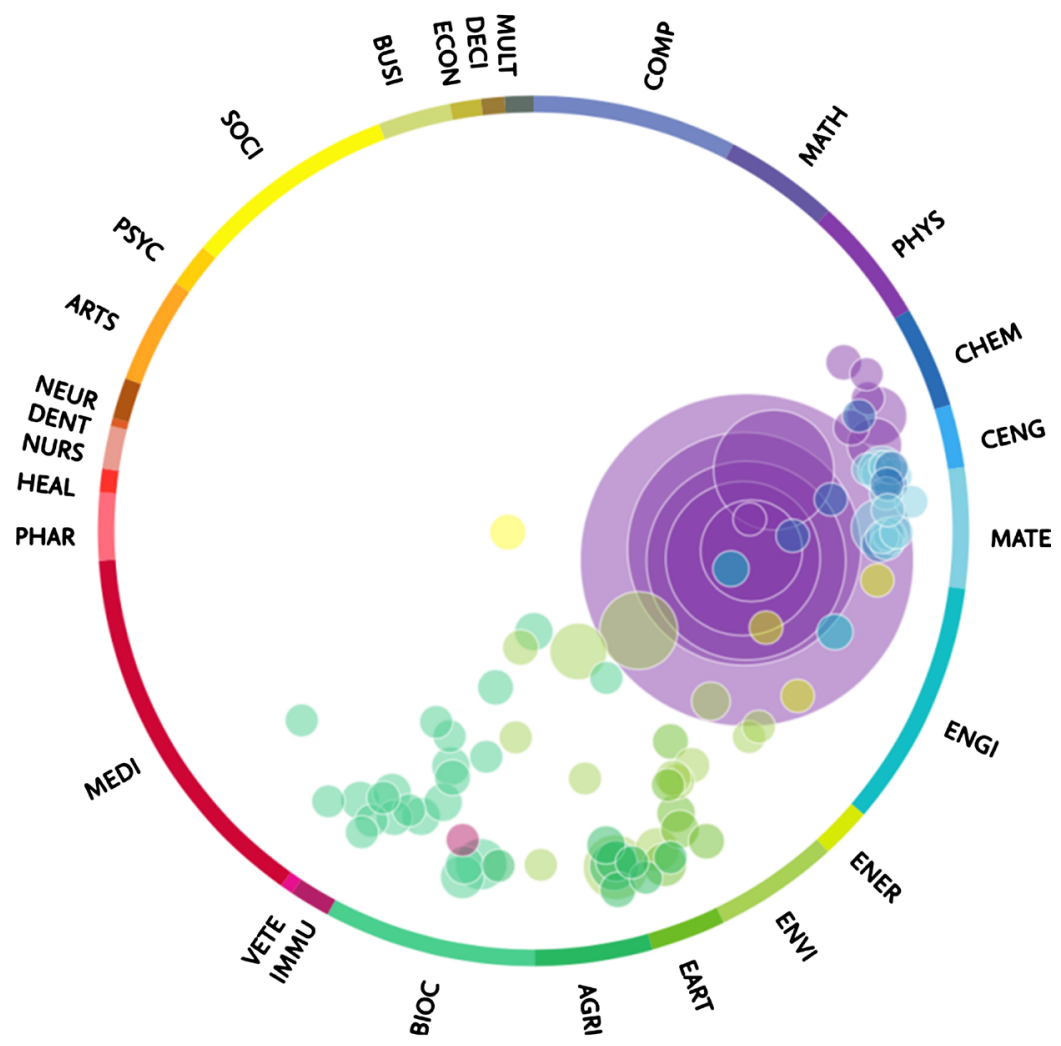

Figure 4. Carnegie endowment for international peace competitiveness analysis round.

number of aggregated documents. The distance from the circle to the center of the circle represents its degree of intersection and discipline composition Weights.

The circle of each document is described by a set of topics. The topic naming method uses Elsevier's fingerprint technology (EFT) and special phrases to create topics in three steps. In actual use, SciVal gives three keywords to describe a topic. The first two keywords are automatically generated by EFT. High-frequency vocabulary is selected to describe the research field and professional direction at a high level. The third keyword is used to select special phrases on this topic to make specific research questions on the topic description of. For example, the subject "galaxies; mass; quiescent galaxies", the research field involves "galaxies and masses", and the specific research content is "static galaxies".

Topic Saliency An indicator that measures topic visibility and development competitiveness. It is calculated from the journal Cite Score index, recent page views, and recent citations. For each topic $j$ s significance $P_{j}$ in the nth year, the calculation formula is as follows:

$$
\begin{aligned}
P_{j}= & \frac{0.495\left(C_{j}-\text { mean }\left(C_{j}\right)\right)}{\operatorname{stdev}\left(C_{j}\right)}+\frac{0.391\left(V_{j}-\text { mean }\left(V_{j}\right)\right)}{\operatorname{stdev}\left(V_{j}\right)} \\
& +\frac{0.1149\left(C S_{j}-\text { mean }\left(C S_{j}\right)\right)}{\operatorname{stdev}\left(C S_{j}\right)}
\end{aligned}
$$

Here $C_{j}$ is the number of citations for topics published in the $n$th and $n-1$ 
years of topic $j, V_{j}$ is the number of Scopus views of topics published in the $n$th and $n-1$ years of topic $j$, and $C S_{j}$ is the number of the average Cite Score for topics of papers published in the $n$th and $n-1$ years, in which the original data has undergone logarithmic transformation, which is Equation (2):

$$
C_{j}=\ln \left(C_{j}+1\right), V_{j}=\ln \left(V_{j}+1\right), C S_{j}=\ln \left(C S_{j}+1\right)
$$

The significance calculation uses standardized scores to eliminate the dimensional difference between the three indicators, and the weighted sum of the discreteness of the number of paper citations, browses, journal evaluation indexes, and averages for that topic in the past two years. The higher the significance value, means the more researchers are paying attention to this topic, indicating that the topic is developing rapidly and is in a high-speed rising stage.

The top $1 \%$ of the highly cited literature topics and indicators of the foundation were used to derive the top 10 topics, and then ranked in descending order according to the significance index to obtain Table 2.

It can be seen from the round chart that the frontier areas of the Carnegie Endowment for International Peace in 2018 are: engineering, materials science, and chemical engineering. There are small-scale research advances in biochemistry, genetic and molecular biology, agricultural biology, earth sciences, and environmental sciences. Among them, the foundation has a large number of achievements in the two major research areas of materials science and engineering, a high degree of interdisciplinary research, and the two disciplines have a very high weight.

From the theme of the subject significance indicator, galaxies, mass, and explosion have appeared more than twice, respectively. It shows that under the two university fields of materials science and engineering, the foundation's research topics around the three key words of galaxy, mass and explosion have a high academic influence, and have been viewed in the number of views, citations and

Table 2. The top ten topics and their indicators.

\begin{tabular}{|c|c|c|c|c|c|c|}
\hline $\begin{array}{l}\text { Topic } \\
\text { ranking }\end{array}$ & Key words & Subject number & $\begin{array}{c}\text { Academic } \\
\text { output }\end{array}$ & $\begin{array}{l}\text { Annual growth } \\
\text { rate (\%) }\end{array}$ & $\begin{array}{l}\text { Normalization } \\
\text { affects factors }\end{array}$ & $\begin{array}{l}\text { theme } \\
\text { Saliency }\end{array}$ \\
\hline 1 & galaxies; mass; quiescent galaxies & T.574 & 115 & -58.1 & 3.24 & 99.585 \\
\hline 2 & supernovae; explosion; circumstellar medium & T.4164 & 95 & 60.5 & 2.63 & 98.83 \\
\hline 3 & supernovae; explosion; maximum light & T.3039 & 78 & -51.3 & 1.88 & 96.123 \\
\hline 4 & planet; planets; planet candidates & T.131 & 77 & -19 & 3.16 & 99.755 \\
\hline 5 & Mercury (planet); mercury (metal); smooth plains & T.7613 & 76 & -72.1 & 2.38 & 89.446 \\
\hline 6 & mass; stars; $\mathrm{L} / \mathrm{T}$ transition & T.2748 & 74 & 157.6 & 1.32 & 95.774 \\
\hline 7 & quasars; active galactic nuclei; broad absorption & T.241 & 64 & -68.8 & 2.59 & 99.211 \\
\hline 8 & debris; disks; differential imaging & T.4806 & 59 & -61 & 2.12 & 97.214 \\
\hline 9 & galaxies; luminosity; high-redshift galaxies & T.5525 & 55 & -56.9 & 3.5 & 98.603 \\
\hline 10 & high pressure; Superconductivity; solid hydrogen & T.12095 & 52 & -50.3 & 2.11 & 98.038 \\
\hline
\end{tabular}


top journals. It is at the leading level in the world. It can be found in the highly-cited literature in the frontier field that the academic output of the frontier topics and the topic significance show a positive correlation trend, which is basically positively linearly related to the annual growth rate, no correlation, and the Field-Weighted Citation Impact Factor.

\section{The Conclusions of the Statistics and Analysis of American First-Class Think Tanks and Their Implications for the Construction of Chinese Think Tanks}

\subsection{Conclusions on Statistics and Analysis of the First-Class Think Tanks in the United States}

Through the statistics, analysis, and induction of the results of five first-class think tanks in the United States, the following conclusions are made on the characteristics of the products of the first-class think tanks in the United States:

First, the achievements of first-class think tanks in the United States are generally diverse. From the perspective of think tank results products, the output of the first-class think tanks in the United States is aimed at different research topics and covers a wide range of subject areas. At the same time, the output is targeted at different customer groups and beneficiaries, and targets different needs. From the perspective of think tank organizations, the functions of most first-class think tanks in the United States are not single. They not only provide services to one party or government, but also provide services to the parties, governments, and citizens. This requires think tanks to set up multiple research departments and hire Experts and researchers in different fields are responsible for the topics in their respective disciplines, which directly results in higher diversity of results.

Second, the products of the first-class think tanks in the United States have expertise in one or several subject areas. Most of the first-class think tanks in the United States with a long history are created by a person or group to solve a problem. For example, the Rand Corporation was in a war period, the Scientific Research and Development Department was established to discuss the development of private organizations and military planning, later developed and researched and helped the federal government to make decisions on major issues, and produced many high-quality results reports on major topics in the military and international relations direction; the Carnegie Endowment for International Peace was developed by Andrew Carnegie Mr. Don, he established a foundation think tank to advance the cause of world peace. The organization has always held a high position in the field of national security and defense. Many first-class think tanks in the United States have their own advantages in one or several areas under the influence of the combined factors of culture, organizational purpose, and researchers' own conditions, and they are also reflected in the output of results.

Third, the top American think tanks dare to speak on sensitive and major star 
issues. Taking Rand Corporation as an example, out of 11,109 documents collected by Scopus with Rand Corporation as an institutional entity, 2591 documents in the field of "Social Science" were selected, and the keywords appeared frequently, and the key of about 1000 documents was found. The words contain sensitive words such as "discrimination" and "gender". Using the Brookings Institution to select the same field for the entity to check the frequency of occurrence of keywords, it was found that "China", "Russian Federation" and other literature that researched on continents, countries or regions accounted for more than $70 \%$ of the overall social science literature. The cultural and political background of the United States allows the country's think tanks to still ensure the independence of the organization's own research, to dare to speak out, and to express its opinions and opinions when selecting research topics or solving major star events.

\subsection{Implications for the Construction of Chinese Think Tanks}

Based on the analysis and research of the first-class think tank results in the United States, as well as the in-depth analysis and exploration of the reasons for the amount of output and influence of the results, combined with the current status of the development of Chinese think tanks, this article proposes the following suggestions for the construction of Chinese think tanks.

\subsubsection{Improve the Independence and Autonomy of Think Tanks' Autonomous Research}

The independence of think tanks' independent research is the fundamental guarantee for the quality of the output of think tanks. As an objective and impartial independent research institution, it conducts research work independently, establishes institutional brands through excellent results products, and improves the organization's influence in society. Relying on, but not completely relying on, government and related department funding to create value through independent research and high-quality results products. Private think tanks carry out multi-level research, not only to provide results and outputs for society and government, but also to meet the needs of enterprises and groups. Multi-level services and output are the bonds that sustain the development of think tanks, especially the development of folk think tanks.

Improving the autonomy of think tank research, establishing a sound research output system, encouraging researchers to set their own questions, exerting the role of subjective imagination, encouraging researchers to innovate, putting forward their own unique insights, and conducting in-depth exploration Research autonomy can increase the enthusiasm of researchers, expand the subject area of think tank research, diversify the results, and meet the needs of a wider range of customers.

\subsubsection{Establish a Sound Think Tank Operation Supervision Mechanism}

Establishing a sound operational supervision mechanism within and outside the 
think tank is an important guarantee for the results of the think tank. Establishing a mature think tank framework system and review and supervision mechanism is indispensable. They can help high-level decision makers in think tanks to understand the development of various topics and results products in a timely manner, meanwhile establish organization and management regulations with clear reward. On the one hand, it guarantees the quality of research and development, and on the other hand, it promotes the continuous improvement of the research level of researchers.

\subsubsection{Encourage Predictive Research on Major Decision-Making Issues}

There is a big gap between the achievements of Chinese think tanks and world-class think tanks on predictive research issues. When making decisions on major issues, statistics and analysis have become important solutions. Under the premise of having advanced technology and tools, the way of predicting and assisting decision-making has been increasingly valued by countries and organizations. In the China Think Tank Index (CTTI) released by the Think Tank Research and Evaluation Center of Nanjing University, there have been more than 120 articles about predictive research, but at the same time, the predictive research results of think tanks on major issues in our country are very few. Establishing forward-looking prediction topics on major issues may become one of the shortcuts for the rapid development of China's think tanks.

\section{Conflicts of Interest}

The authors declare no conflicts of interest regarding the publication of this paper.

\section{References}

[1] Cui, Y.H. (2018) Research on Frontier Topic Detection and Feature Analysis Based on Global Micromodel. Library and Information Service, 62, 75-82.

[2] Guo, B. (2018) Research on Strategies for Increasing the Influence of Think Tank's Overall Products. Information Magazine, No. 9, 86-92.

[3] Xu, Z.W. (2012) Principle of SciVal Spotlight Evaluation Index and Comparative Study with ESI. Library and Information Service, No. 14, 86-92.

[4] Zhang, X. (2018) Reflections on the Dilemma and Construction of Chinese Think Tank Evaluation System. Information Magazine, No. 8, 68-70.

[5] Cao, J. (2016) Investigation Analysis and Enlightenment of Think Tank Results in Foreign Universities. Journal of Information, 35, 59-64.

[6] Ren, H. (2018) Research on the Connotation Characteristics, Operation Mechanism and Optimization Strategies of Chinese Think Tank Market. Journal of Information, 37, 7-14. http://kns.cnki.net/kcms/detail/61.1167.G3.20180820.1358.004.html

[7] Xia, C.H. (2013) Comparative Study on External Environmental Factors of Chinese and American Think Tanks. Frontiers, No. 1, 7-9.

[8] Fu, G.W. (2017) Differential Policy Analysis of Think Tank Development Path. Nanjing Social Sciences, No. 9, 7-19.

[9] Feng, X.B. (2018) Knowledge Base and Hot Trend of Corporate Reverse Internatio- 
nalization Research, Bibliometric Analysis Based on Web of Science. Journal of Zhejiang University of Science and Technology, No. 10, 449-458.

[10] Song, Z.H. (2018) RAND's Product Overview and Enlightenment of Output Strategy. Information Magazine, No. 6, 27-32.

[11] Luan, R.Y. (2017) Carnegie Endowment for International Peace. Social Science Abstracts, No. 9, 8-10.

[12] Qi, Y. (2016) Brookings Institution of 100 Years: From helping decision-making to improving governance. Social Governance, No. 6, 137-140.

[13] McGann, J. (2018) Global Think Tank Report 2017. University of Pennsylvania, Pennsylvania, PA.

[14] Weeks, J.M. (2011) The Carnegie institution of Washington current reports, 1952-1957.

[15] Winthrop, R. (2014) The Case for Global Education. Brookings Institution, How Think Tanks Shape Social Development Policies, 65-75.

[16] Rescher, N. (2018) Early RAND as a Talent Incubator: An Extraordinary Experiment. Independent Review, 22, 417-427. 